\title{
Working
}

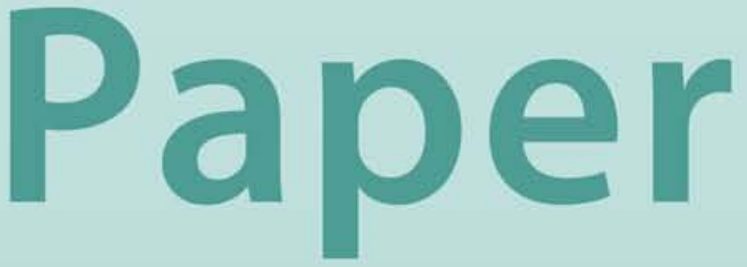


Nominal Exchange Rate Anchoring Under Inflation Inertia

Guillermo Calvo, Oya Celasun and

Michael Kumhof 


\title{
IMF Working Paper
}

\author{
Research and Middle Eastern Departments
}

\section{Nominal Exchange Rate Anchoring Under Inflation Inertia}

\author{
Prepared by Guillermo Calvo, Oya Celasun and Michael Kumhof * \\ Authorized for distribution by Ashoka Mody and Paul Chabrier
}

February 2002

\begin{abstract}
The views expressed in this Working Paper are those of the author(s) and do not necessarily represent those of the IMF or IMF policy. Working Papers describe research in progress by the author(s) and are published to elicit comments and to further debate.
\end{abstract}

This paper develops a theory of inflation inertia based on forward looking staggered price setting in the nontradable goods sector of a small open economy. Unlike current theories of sticky prices, transitions to a lower steady state inflation rate take time even if they are fully credible, and they are associated with significant output losses in nontradables There is a welfare trade-off between these output losses and the gains from smaller inflationary distortions. Gains exceed losses for most calibrations. The optimal steady state is the Friedman rule.

\section{JEL Classification Numbers: E31, E52, F41}

Keywords: Inflation inertia, staggered pricing, exchange rate based stabilization

Authors’ E-Mail Address: Gcalvo@iadb.org; Ocelasun@imf.org; Mkumhof@imf.org

\footnotetext{
"Guillermo Calvo: Chief Economist at the Inter-American Development Bank and Professor at the University of Maryland; Oya Celasun: Economist, Middle Eastern Department: and Michael Kumhof: Economist, Research Department and Assistant Professor at Stanford University. The authors would like to thank Fernando Alvarez, Jeff Campbell, Charles Engel, Timothy Kehoe, Alejandro Micco, Michael Mussa, Lars Svensson, John Taylor, Ken West, and seminar participants at Chicago GSB, Stanford, Wisconsin, the 2001 Latin American Meetings of the Econometric Society, and the 2001 Winter Camp in Santiago, Chile, for helpful comments.
} 


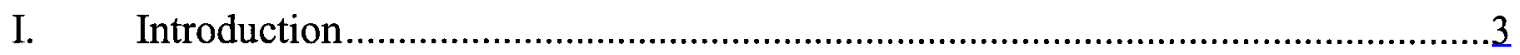

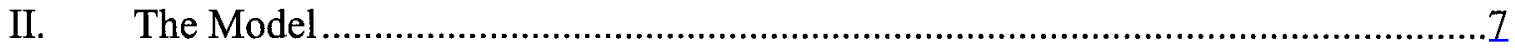

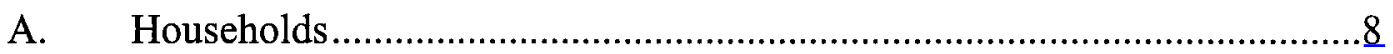

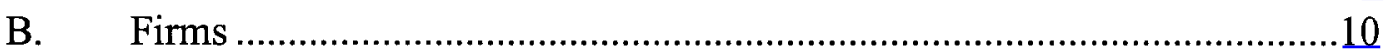

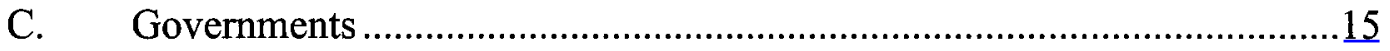

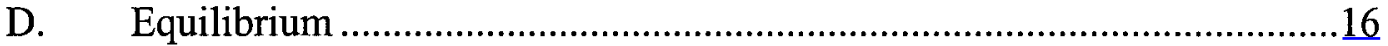

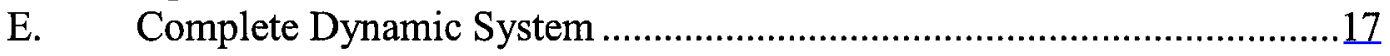

III. Model Solution and Discussion .............................................................19

A. Permanent Policies .............................................................................21

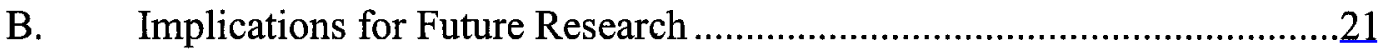

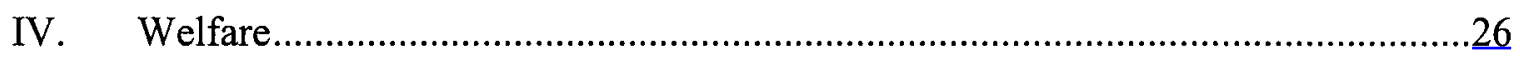

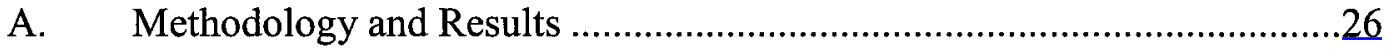

B. Implications for Future Research.................................................29

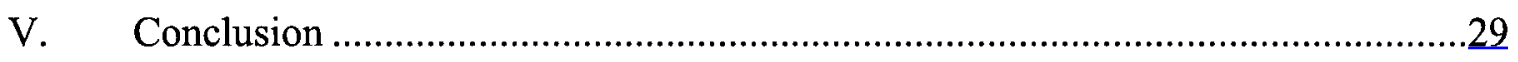

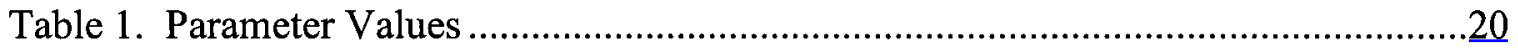

Text Figures:

1. Approximating the Optimal Price Path.................................................5

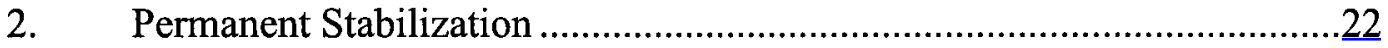

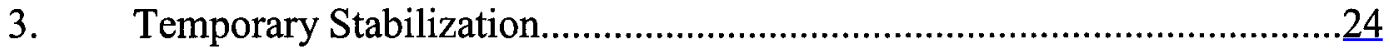

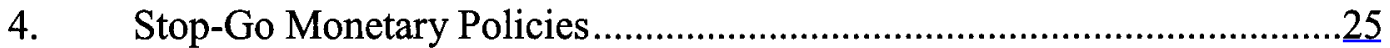

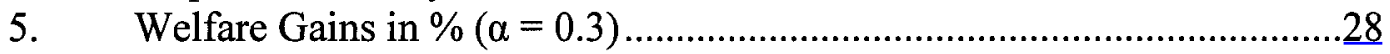

Appendices:

I. The Relationship between Labor Supply

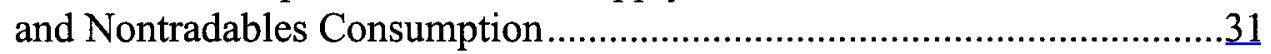

II. Roots of the Dynamic System...................................................

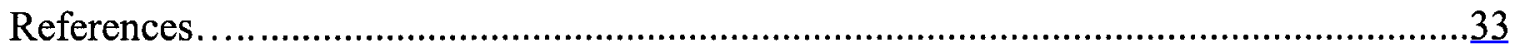


"If there is such a thing as an economy with a rock-solid inflation rate of 40 per cent, plus or minus 2 per cent, per year, institutions would surely adapt, so that prices would be announced in catalogs and wage contracts with smooth growth paths paralleling the smooth aggregate price path. Nominal rigidity would set in about this price path in much the same form as we see around the zero inflation rate in low-inflation economies." (Sims, 1988, p. 77)

\section{Introduction}

Much of modern monetary theory uses optimizing forward-looking dynamic general equilibrium models incorporating, in one form or another, the assumption of sticky prices. A comprehensive survey of this literature is contained in Clarida, Gali and Gertler (1999) for closed economies, and Lane (2001) for open economies. The renewed popularity of sticky price monetary economics was motivated by empirical findings which demonstrated, at least for the US case, that monetary policy has significant real effects, contrary to the premise of the real business cycle literature. Examples of that empirical literature include Christiano, Eichenbaum and Evans $(1996,1998)$ and Leeper, Sims and Zha (1996). As surveyed in Taylor (1998), the assumption of sticky prices does a good job in explaining most features of those data. That paper also documents the micro- and macroeconomic evidence supporting the assumption of sticky prices itself.

Despite its undoubted successes, this research strategy has nevertheless left some important puzzles unsolved. The one which this paper will address, in the specific context of a small open economy targeting the nominal exchange rate, is probably the most prominent. It is the failure to generate endogenous inflation persistence, an important feature of the data. The models of forward looking nominal contracts surveyed in Clarida, Gali and Gertler (1999) are only able to generate inflation persistence with the help of serially correlated exogenous shocks, e.g. money supply shocks. As pointed out by Taylor (1998) this is not completely satisfactory since the response of inflation to serially uncorrelated money shocks 
is very persistent. To circumvent these difficulties the literature has therefore also relied on less than fully forward looking pricing behavior or on contracting specifications that are not derived from explicit microfoundations, as in Fuhrer and Moore (1995) and a section in Clarida, Gali and Gertler (1999).

Inertia of the inflation rate has been found in a large body of empirical work. For the case of the US, there is an ongoing debate on the extent to which inflation inertia is attributable to backward looking pricing behavior. The conventional sticky price model only admits forward looking inflation terms in estimating equations for inflation dynamics. Fuhrer and Moore (1995) and Fuhrer (1997) document the difficulties of that model in matching the degree of inflation persistence found in the data. Gali and Gertler (1999) and Gali, Gertler and Lopez-Salido (2001), however, using a different model specification that emphasizes the importance of marginal costs in pricing, estimate that forward looking terms are more important in inflation dynamics than backward looking terms. For the case of two high inflation economies, Mexico and Turkey, Celasun (2000 a, b) finds that inflation in the tradables sector exhibits a degree of stickiness which is close to that implied by the results of Gali and Gertler (1999) for the US, whereas inflation in the nontradables sector displays a high degree of inertia captured by significant lagged terms in a structural equation for inflation dynamics.

In our view a very important source of difficulties with the current generation of sticky price models can be seen much more clearly once one starts to think about price setting in environments with significantly above zero steady state inflation, such as many emerging markets. Sticky price models stipulate that firms / workers cannot continuously adjust their prices / wages, either because of an exogenous arrival process for price changing opportunities as in Calvo $(1983)^{1}$, because of staggered and overlapping contracts of fixed length as in Taylor (1979), or because of exogenous costs of adjusting prices as in

\footnotetext{
1 The Calvo (1983) specification is used in much of current research due to its analytical tractability. For examples see Yun (1996), King and Wolman (1996), and Woodford (1996).
} 
Rotemberg (1982). Importantly however, at the times when price setters do reset their prices they choose only a price level. While this may be a sensible assumption in an environment of near zero steady state inflation, it is far more questionable under two-digit steady state inflation rates. Figure 1 illustrates our argument. If we think of firms as wanting to remain as close as possible to their flexible price optimum at all times, but being prevented from doing so by price rigidities, most current models amount to stipulating that firms have to choose their schedule of (logarithms of) future actual prices by fitting a zero slope regression line through (logarithms of) future optimal prices. The latter however continuously rise. The great drawback of this approach is that an increase in steady state inflation must then give rise to a greater dispersion of relative prices and consequently to lower steady state output. With significantly nonzero steady state inflation this real effect is of nontrivial magnitude. Many would consider this type of long-run monetary nonneutrality to be an undesirable feature of the model.

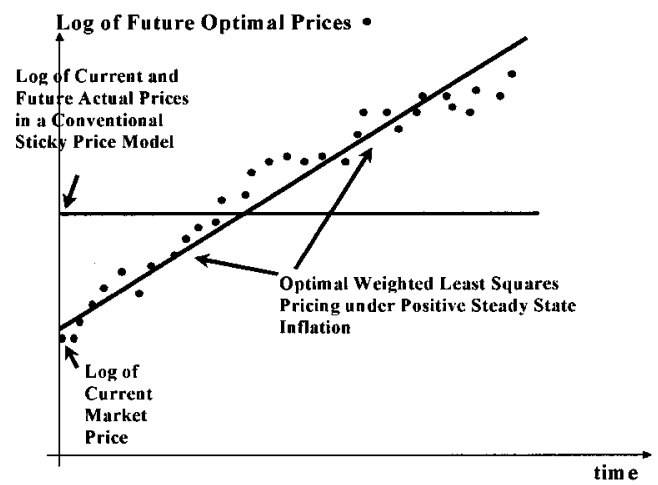

Figure 1: Approximating the Optimal Price Path

In our view, firms in such environments can more usefully be thought of as continuously adjusting their prices according to some pricing rule which is only updated at infrequent intervals, again because of adjustment costs or a Calvo or Taylor staggering rule. ${ }^{2}$ In our model we therefore give firms one more choice variable, by letting them choose both today's price level and the rate at which they will update prices in the future, a 'firm-specific

\footnotetext{
2 Taylor (1983) contains evidence for this type of behavior in the US labor market in the 1970s.
} 
inflation rate'. In terms of the regression analogy, this amounts to fitting a weighted least squares regression line through future optimal prices. In an environment of non-zero steady state inflation this assumption is much less restrictive than the standard one.

An alternative formulation which has been proposed in the literature, starting with Yun (1996), is that price-setting firms choose their current price level and update prices at the steady state inflation rate thereafter, typically in an environment where the steady state itself does not change. This approach, which in steady state is identical to ours, avoids the above mentioned long-run monetary nonneutrality and as such is certainly very useful. But it may be problematic when thinking about transitions between different steady states, because it amounts to assuming that when the steady state itself changes all firms, including those who are unable to change their current price level, nevertheless immediately change their updating rule. That may still be an appropriate description of firm behavior when the change in the steady state inflation rate is very large, so that taking the news of this change into account would be a very high priority for price setters. But when the change in steady state inflation is moderate our assumption appears more plausible. Future research to endogenize this element of state dependency would evidently be highly desirable. In the meantime, we view our approach and the Yun (1996) approach as complementary.

When firms behave in the fashion we propose and the monetary policy rule changes, the economy contains a large number of firms that have formulated their pricing policies under the previous policy. This gives rise to inflationary inertia, meaning that in response to the unexpected announcement of a permanently and credibly lower growth rate of the nominal anchor the economy cannot immediately transition to its new steady state - this can only happen once all firms have changed their pricing policies. The disinflation period is also associated with significant output losses. This is in marked contrast to Calvo-Yun sticky price models, for which Ball (1994a) and, in the context of an exchange rate based stabilization in a small open economy, Calvo and Vegh (1993) have shown that a permanent and credible reduction in the growth rate of the nominal anchor reduces inflation at a stroke 
and without a recession. That prediction is not in line with experience even in countries where the monetary authority enjoys a high degree of credibility, as shown by Ball (1994b). Lack of credibility, as in Ball (1995) or Calvo and Vegh (1993), would give rise to inflation persistence, but it is not clear that credibility has always been an issue in the episodes where inflation persistence was observed.

The above intuitive motivation for our theoretical approach is based on considering economies with well above zero steady state inflation, such as emerging markets. We therefore choose as the first application of our pricing formulation a model of exchange rate targeting in small open emerging economies. ${ }^{3}$ Inflation inertia has in fact been one of the major issues in the application of that policy (Calvo and Vegh (1999)). Empirical tests of the pricing model based on Mexican data, and reported in Calvo, Celasun and Kumhof (2001), are supportive of our specification.

The rest of the paper is organized as follows. Section II presents the model. Section III calibrates the model and computes solution paths for some monetary policy experiments including a permanent and a temporary reduction in the rate of exchange rate depreciation. Section IV evaluates the welfare trade-off between the output losses and efficiency gains of disinflation. Section V concludes. Some technical details and proofs are contained in two appendices.

\section{The Model}

Consider a small open economy which consists of a government, a continuum of measure one of identical price-taking infinitely-lived households, and a continuum, indexed by $j \in[0,1]$, of monopolistically competitive infinitely-lived nontradable goods producing firms. The economy trades goods with the rest of the world, and for the prices of these

\footnotetext{
3 The question of whether the mechanism we propose is also a good explanation for US inflationary inertia is left for future research, but we certainly consider it a promising candidate. Our theory of price setting is very general and can be embedded in any monetary policy environment.
} 
tradable goods purchasing power parity is assumed to hold. Normalizing the foreign price level to one this implies that the nominal price of tradables equals the nominal exchange rate $E_{t}$. The nominal price level of nontradable goods is denoted by $P_{t}$, and the associated inflation rate by $\pi_{t}=\dot{P}_{t} / P_{t}$. The relative price of tradables and nontradables, which will be referred to as the real exchange rate, is $e_{t}=E_{t} / P_{t}$. The economy can also freely borrow from or lend to the rest of the world, and uncovered interest parity is assumed to hold:

$$
i_{t}=r+\varepsilon_{t}
$$

Here $r$ is the exogenous, constant and positive real international interest rate, $\varepsilon_{t}=\dot{E}_{t} / E_{t}$ is the rate of exchange rate depreciation, and $i_{t}$ is the nominal interest rate on domestic currency denominated assets.

\section{A. Households}

Households maximize lifetime utility, which depends on their consumption of homogenous tradable goods $c_{t}^{*}$, heterogeneous nontradable goods $c_{t}(j), j \in[0,1]$, and utility from leisure $1-L_{t}$, where 1 is the fixed endowment of time and $L_{t}$ is total labor supply to firms. To rule out inessential dynamics households' personal discount rate is assumed to equal the real international interest rate $r$. Aggregate nontradables consumption is given by

$$
c_{t}=\left(\int_{0}^{1} c_{t}(j)^{\frac{\sigma-1}{\sigma}} d j\right)^{\frac{\sigma}{\sigma-1}},
$$

with elasticity of substitution $\sigma>1$. Let $P_{t}(j)$ be the price of individual good $c_{t}(j)$. Then cost minimization implies

$$
c_{t}(j)=c_{t}\left(\frac{P_{t}(j)}{P_{t}}\right)^{-\sigma},
$$

where the price index of nontradables $P_{t}$ is

$$
P_{t}=\left(\int_{0}^{1} P_{t}(j)^{1-\sigma} d j\right)^{\frac{1}{1-\sigma}}
$$


The representative household's objective function is

$$
\operatorname{Max} \int_{0}^{\infty}\left[\gamma \ln \left(c_{t}^{*}\right)+(1-\gamma) \ln \left(c_{t}\right)+\kappa \ln \left(1-L_{t}\right)\right] e^{-r t} d t .
$$

This specification is similar to King and Wolman (1996) except that it allows for both tradable and nontradable goods. Households are subject to a cash in advance constraint for their purchases of tradables and nontradables:

$$
m_{t} \geq \alpha\left(c_{t}^{*}+\frac{c_{t}}{e_{t}}\right)
$$

Here $m_{t}\left(M_{t}\right)$ are real (nominal) money balances, with $m_{t}=M_{t} / E_{t}$, and $\alpha$ is constant inverse velocity. The opportunity cost of holding one unit of money is equal to the nominal interest rate, which given our assumption of predetermined positive exchange rate depreciation (see below) and uncovered interest parity must be greater than zero. The cash-in-advance constraint will therefore be binding at all times. Apart from money households also hold international bonds denominated in units of tradable goods $b_{t}$, with real interest rate $r$. Households receive a fixed endowment of tradable goods $y^{*}$, and identical government lump-sum transfers in terms of tradables $\tau_{t}$. From firms they receive nominal wages $W_{t} L_{t}$ and identical nominal lump-sum profit distributions $\int_{0}^{1} \Pi_{t}(j) d j{ }^{4}$ Their flow budget constraint is

$$
\dot{b}_{t}=r b_{t}-\dot{m}_{t}-\varepsilon_{t} m_{t}+y^{*}-c_{t}^{*}+\tau_{t}+\frac{W_{t} L_{t}}{E_{t}}+\frac{\int_{0}^{1} \Pi_{t}(j) d j}{E_{t}}-\frac{\int_{0}^{1} P_{t}(j) c_{t}(j) d j}{E_{t}} .
$$

After imposing the no Ponzi games condition $\lim _{t \rightarrow \infty}\left(b_{t}+m_{t}\right) e^{-r t} \geq 0$, we can write their lifetime budget constraint as

$$
\begin{aligned}
& b_{0}+m_{0}+\int_{0}^{\infty}\left(y^{*}+\tau_{t}+\frac{W_{t} L_{t}}{E_{t}}+\frac{\int_{0}^{1} \Pi_{t}(j) d j}{E_{t}}\right) e^{-r t} d t \\
\geq & \int_{0}^{\infty}\left(c_{t}^{*}+\frac{\int_{0}^{1} P_{t}(j) c_{t}(j) d j}{E_{t}}+i_{t} m_{t}\right) e^{-r t} d t .
\end{aligned}
$$

\footnotetext{
4 The assumption of identical transfers insures that households remain identical at all times because the wealth distribution remains unchanged.
} 
The representative household maximizes (5) subject to (6) and (8), with (6) binding. The first order conditions are (8) holding with equality, (3) and

$$
\begin{gathered}
\frac{\gamma}{c_{t}^{*}}=\lambda\left(1+\alpha i_{t}\right), \\
\frac{c_{t}}{c_{t}^{*}}=e_{t} \frac{1-\gamma}{\gamma}, \\
w_{t} \equiv \frac{W_{t}}{P_{t}}=\frac{\kappa c_{t}\left(1+\alpha i_{t}\right)}{\left(1-L_{t}\right)(1-\gamma)} .
\end{gathered}
$$

Here $\lambda$ is the constant multiplier of the lifetime budget constraint (8), equal to the shadow value of lifetime wealth. Equation (9) equates the marginal utility of tradables consumption to the marginal utility of wealth times the effective price of consumption, the latter being equal to the purchase price plus the cost of holding the money balances necessary to conduct transactions. Equation (10) equates the marginal rate of substitution between tradables and nontradables to their relative price, the real exchange rate. Equation (11) equates the real wage to the marginal rate of substitution between consumption and leisure, corrected for a monetary distortion. The latter is increasing in deviations from the Friedman rule.

\section{B. Firms}

We assume that price rigidities are limited to the nontradable goods sector. The assumption of purchasing power parity for tradable goods calls for some further comments. Excellent surveys of the literatures on purchasing power parity, exchange rate pass-through and pricing-to-market can be found in Froot and Rogoff (1995), Goldberg and Knetter (1997) and Menon (1995). ${ }^{5}$ The latter shows that until very recently all of the evidence related to developed countries. According to Goldberg and Knetter (1997), the consensus estimate of the US pass-through coefficient is 0.5-0.6 after one year, but as shown for example in Campa and Goldberg (2001) it is significantly higher for smaller developed economies, and higher yet for the emerging economies studied by Webber (1999). A new

\footnotetext{
5 The textbook definition of the pass-through coefficient is the elasticity of domestic currency imported goods prices with respect to a change in the nominal exchange rate.
} 
study by Goldfajn and Werlang (2000) estimates a coefficient of 0.912 after one year for emerging economies and 0.605 for developed countries. Central banks in emerging economies stress the importance of high pass-through for their monetary policies, see Carstens and Werner (1999) for Mexico and Morande and Schmidt-Hebbel (2000) for Chile. These findings are consistent with the (stylized) assumptions of the model: First, exogenous world prices mean that all exporters price to the large developed economies, with a pass-through coefficient of zero. Second, purchasing power parity means that pass-through to the small open economy's domestic currency prices is complete. Taken together with the assumption of price rigidities in the nontradables sector, purchasing power parity implies that all movements in the consumer price index based real exchange rate are driven by movements in the relative price of tradables and nontradables $e_{t}$. This is directly contrary to the evidence for the US presented in Engel (1999), who finds that almost all movements in that broad measure of the real exchange rate are accounted for by changes in the relative price of tradables. However, there is empirical evidence showing that in emerging markets the relative price of tradables and nontradables exhibits very large fluctuations. See e.g. Mendoza (2000).

Firms are distributed uniformly along the unit interval and have linear production functions in labor input $l_{t}(j)$ :

$$
y_{t}(j)=l_{t}(j), \quad j \in[0,1] .
$$

They are price takers in the labor market and monopolistically competitive in the goods market. Firms distribute all nominal profits $\Pi_{t}(j)$ to households in a lump-sum fashion:

$$
\Pi_{t}(j)=P_{t}(j) c_{t}(j)-W_{t} l_{t}(j), \quad j \in[0,1]
$$

Following Calvo (1983), it is assumed that firms only get infrequent opportunities to change their prices, and that these opportunities arrive as exogenous random processes. For each firm they follow an exponential distribution with probability density $\delta e^{-\delta t}$, and are therefore independent of their last occurrence. They are also independent across firms. 
This allows the application of a law of large numbers and implies that there is no aggregate uncertainty. Together with the assumption of identical lump-sum profit distributions this implies that firm-specific uncertainty does not translate into income uncertainty for the representative household. In the following derivations we make use of the following two properties of exponential distributions:

$$
\delta \int_{t}^{\infty}(s-t) e^{-\delta(s-t)} d s=\frac{1}{\delta} \quad, \quad \delta \int_{t}^{\infty}(s-t)^{2} e^{-\delta(s-t)} d s=\frac{2}{\delta^{2}}
$$

Following Yun (1996) and Woodford (1996), firms are assumed to maximize the present discounted value of real future profits each time they are allowed to change prices. Their discount rate is the own rate of interest for nontradable goods $r+\varepsilon_{t}-\pi_{t}$, and in addition they weight profits at each future time by the probability that today's price will still be in force. Firms' real marginal cost equals the real wage in terms of nontradables $w_{t}=W_{t} / P_{t}$, where $W_{t}$ and $P_{t}$ are taken as given. Crucially for this paper, whenever firms do receive a price changing opportunity they determine an optimal price schedule, consisting of today's price level $V_{t}^{j}$ and a 'firm specific inflation rate' $v_{t}^{j}$. If the price schedule of product variety $j$ was last set at time $t$, we therefore have for all $s>t$ that

$$
P_{s}(j)=V_{t}^{j} e^{v_{t}^{j}(s-t)} .
$$

Firms maximize

$$
\underset{V_{t}^{j}, v_{t}^{j}}{\operatorname{Max}} \int_{t}^{\infty} e^{-\int_{t}^{s}\left(\delta+r+\varepsilon_{r}-\pi_{r}\right) d r}\left[\frac{V_{t}^{j} e^{v_{t}^{j}(s-t)}}{P_{s}} y_{s}(j)-w_{s} l_{s}(j)\right] d s,
$$

subject to the production function (12), and subject to goods demand (3). Given (14) the goods demand can, for $s>t$, be written as

$$
y_{s}(j)=c_{s}\left(\frac{V_{t}^{j} e^{v_{t}^{j}(s-t)}}{P_{s}}\right)^{-\sigma} .
$$

Note that the maximization problem is identical for all firms that receive a price changing opportunity, so that the firm index $j$ can be dropped in stating the first order conditions. For 
$V_{t}$ we have

$$
\int_{t}^{\infty} e^{-\int_{t}^{s}\left(\delta+r+\varepsilon_{r}-\pi_{r}\right) d r} c_{s}\left(\frac{V_{t} e^{v_{t}(s-t)}}{P_{s}}\right)^{-\sigma}\left[\frac{V_{t} e^{v_{t}(s-t)}}{P_{s}}-\frac{\sigma}{\sigma-1} w_{s}\right] d s=0 .
$$

We define the new variable $p_{t} \equiv V_{t} / P_{t}$, the initial relative price of new price setters. Note also that, for $s>t, P_{s}=P_{t} e^{\int_{t}^{s} \pi_{r} d r}$. Then we can rewrite the last condition as

$$
\int_{t}^{\infty} e^{-\int_{t}^{s}\left(\delta+r+\varepsilon_{r}-\pi_{r}\right) d r} c_{s}\left(p_{t} e^{-\int_{t}^{s}\left(\pi_{r}-v_{t}\right) d r}\right)^{-\sigma}\left[p_{t} e^{-\int_{t}^{s}\left(\pi_{r}-v_{t}\right) d r}-\frac{\sigma}{\sigma-1} w_{s}\right] d s=0 .
$$

Steady state values will be denoted by a bar above the respective variable. Note that in steady state, for a constant rate of exchange rate depreciation $\bar{\varepsilon}$, we must have $\bar{\pi}=\bar{v}=\bar{\varepsilon}$ and $\bar{p}=1$. The steady state real wage therefore follows from (17) as $\bar{w}=(\sigma-1) / \sigma$. The first-order condition for $v_{t}$ can similarly be derived as

$$
\int_{t}^{\infty} e^{-\int_{t}^{s}\left(\delta+r+\varepsilon_{r}-\pi_{r}\right) d r} c_{s}\left(p_{t} e^{-\int_{t}^{s}\left(\pi_{r}-v_{t}\right) d r}\right)^{-\sigma}(s-t)\left[p_{t} e^{-\int_{t}^{s}\left(\pi_{r}-v_{t}\right) d r}-\frac{\sigma}{\sigma-1} w_{s}\right] d s=0
$$

Next we linearize (17) and (18) around the steady state. For the real wage it is more convenient to $\log$-linearize, and we therefore define the new variable $\xi_{t}=\ln \left(w_{t}\right)$. The following expressions are obtained:

$$
\begin{gathered}
p_{t}+\frac{v_{t}}{\delta+r}=(\delta+r) \int_{t}^{\infty} e^{-(\delta+r)(s-t)}\left[1+\left(\xi_{s}-\bar{\xi}\right)+\int_{t}^{s} \pi_{r} d r\right] d s=0 \\
\frac{p_{t}}{\delta+r}+\frac{2 v_{t}}{(\delta+r)^{2}}=(\delta+r) \int_{t}^{\infty} e^{-(\delta+r)(s-t)}(s-t)\left[1+\left(\xi_{s}-\bar{\xi}\right)+\int_{t}^{s} \pi_{r} d r\right] d s=0
\end{gathered}
$$

The derivatives with respect to time of these expressions are

$$
\begin{gathered}
\dot{p}_{t}+\frac{\dot{v}_{t}}{\delta+r}=(\delta+r)\left(p_{t}-1-\left(\xi_{t}-\bar{\xi}\right)\right)+v_{t}-\pi_{t}, \\
\dot{p}_{t}+\frac{2 \dot{v}_{t}}{\delta+r}=v_{t}-\pi_{t} .
\end{gathered}
$$

We combine (21) and (22) to obtain the following differential equation for the firm-specific inflation rate $v_{t}$ :

$$
\dot{v}_{t}=-(\delta+r)^{2}\left(\left(p_{t}-1\right)-\left(\xi_{t}-\bar{\xi}\right)\right)
$$


It is clear that $v_{t}$ is a jump variable. When there is a discrete change in the monetary policy regime it will be optimal for firms receiving a price changing signal to allow discrete changes in both their current price and their firm specific inflation rate.

To complete the description of price dynamics we now turn to the aggregate price index. When firms set prices in the manner specified above, the index (4) can be rewritten as

$$
P_{t}=\left(\delta \int_{-\infty}^{t} e^{-\delta(t-s)}\left(V_{s} e^{v_{s}(t-s)}\right)^{1-\sigma} d s\right)^{\frac{1}{1-\sigma}} .
$$

To obtain an expression for the aggregate inflation rate we first take the derivative of (24) with respect to time. We obtain:

$$
\pi_{t}=\frac{\delta}{1-\sigma}\left(p_{t}^{1-\sigma}-1\right)+\delta \int_{-\infty}^{t} e^{-\delta(t-s)}\left(p_{s} e^{-\int_{s}^{t}\left(\pi_{r}-v_{s}\right) d r}\right)^{1-\sigma} v_{s} d s .
$$

Next we linearize this expression around the steady state. Remember that the steady state inflation rate equals $\bar{\varepsilon}$ for all rates of price change, and that $\vec{p}=1$ :

$$
\left(\pi_{t}-\bar{\varepsilon}\right)=\delta\left(p_{t}-1\right)+\delta \int_{-\infty}^{t} e^{-\delta(t-s)}\left[\left(v_{s}-\bar{\varepsilon}\right)+\bar{\varepsilon}(1-\sigma)\left(\left(p_{s}-1\right)-\int_{s}^{t}\left(\pi_{r}-v_{s}\right) d r\right)\right] d s
$$

This expression can be simplified by realizing that the price index (24) can, after applying the normalization introduced in (17) and (18), itself be linearized around the steady state as

$$
\delta \int_{-\infty}^{t} e^{-\delta(t-s)}(1-\sigma)\left(\left(p_{s}-1\right)-\int_{s}^{t}\left(\pi_{r}-v_{s}\right) d r\right) d s=0 .
$$

Substituting this expression into (26) we obtain

$$
\left(\pi_{t}-\bar{\varepsilon}\right)=\delta\left(p_{t}-1\right)+\delta \int_{-\infty}^{t} e^{-\delta(t-s)}\left(v_{s}-\bar{\varepsilon}\right) d s .
$$

We now define a new variable $\psi_{t}$ as the weighted average of currently 'active' firm-specific inflation rates

$$
\psi_{t}=\delta \int_{-\infty}^{t} e^{-\delta(t-s)} v_{s} d s
$$

This variable is of course predetermined, and its time derivative is

$$
\dot{\psi}_{t}=\delta\left(v_{t}-\bar{\varepsilon}\right)-\delta\left(\psi_{t}-\bar{\varepsilon}\right)
$$


Using the definition of $\psi_{t}$ we can rewrite the expression for aggregate inflation as

$$
\left(\pi_{t}-\bar{\varepsilon}\right)=\delta\left(p_{t}-1\right)+\left(\psi_{t}-\bar{\varepsilon}\right)
$$

This is a key equation. The second term reflects inertia in the aggregate inflation rate through the historic pricing policies of firms which have not yet received a price changing opportunity. This term will turn out to dominate the overall dynamics of $\pi_{t}$. The first term, the relative price of new price setters $p_{t}$, is free to jump at time 0 . Therefore, despite the presence of an inertial component, aggregate inflation is a free or jump variable. Its derivative with respect to time is found, after some algebra, to equal

$$
\dot{\pi}_{t}=-(3 \delta+2 r)\left(\psi_{t}-\bar{\varepsilon}\right)+2 \delta\left(v_{t}-\bar{\varepsilon}\right)+(\delta+2 r)\left(\pi_{t}-\bar{\varepsilon}\right)-2 \delta(\delta+r)\left(\xi_{t}-\bar{\xi}\right)
$$

Expression (31) can also be used to rewrite the differential equation for firm-specific inflation as

$$
\dot{v}_{t}=\frac{(\delta+r)^{2}}{\delta}\left(\psi_{t}-\bar{\varepsilon}\right)-\frac{(\delta+r)^{2}}{\delta}\left(\pi_{t}-\bar{\varepsilon}\right)+(\delta+r)^{2}\left(\xi_{t}-\bar{\xi}\right)
$$

The system of differential equations (30), (32) and (33) in $\psi, \pi$ and $v$ must be closed with a fourth equation for the $\log$ of real marginal cost $\xi$, derived from (11), to fully characterize the dynamic behavior of this economy. To do so we must first describe government behavior and define equilibrium.

\section{Government}

The government owns a stock of net foreign assets $h_{t}$, issues money $M_{t}$, and makes lump-sum transfers $\tau_{t}$. Its flow budget constraint is

$$
\dot{h}_{t}=r h_{t}+\dot{m}_{t}+\varepsilon_{t} m_{t}-\tau_{t}
$$

By imposing the transversality condition $\lim _{t \rightarrow \infty}\left(h_{t}-m_{t}\right) e^{-r t}=0$ one obtains the government's lifetime constraint

$$
h_{0}-m_{0}+\int_{0}^{\infty}\left(i_{t} m_{t}-\tau_{t}\right) e^{-r t} d t=0
$$


A government policy is defined as a list of time paths $\left\{E_{t}, \tau_{t}\right\}_{t=0}^{\infty}$ such that, given the time path $\left\{m_{t}\right\}_{t=0}^{\infty}$, the constraint (34) holds. In particular, lump-sum redistributions are assumed to be Ricardian while exchange rate policy takes one of the following forms:

\section{Permanent Stabilization}

The government reduces inflation by a surprise announcement at time 0 of a permanently lower rate of exchange rate depreciation:

$$
\begin{aligned}
\varepsilon_{t} & =\varepsilon^{h}, t \in(-\infty, 0), \\
\varepsilon_{t} & =\varepsilon^{l}, t \in[0, \infty) .
\end{aligned}
$$

\section{Temporary Stabilization}

Under this policy the government also announces a lower rate of exchange rate depreciation, but this is correctly anticipated by the public to be of only limited duration:

$$
\begin{aligned}
\varepsilon_{t} & =\varepsilon^{h}, t \in(-\infty, 0), \\
\varepsilon_{t} & =\varepsilon^{l}, t \in[0, T), \\
\varepsilon_{t} & =\varepsilon^{h}, t \in[T, \infty) .
\end{aligned}
$$

\section{Equilibrium}

The list of time paths $\left\{b_{t}, h_{t}, m_{t}, c_{t}^{*}, y_{t}^{*}, L_{t}, c_{t}, l_{t}(j), c_{t}(j), y_{t}(j), j \in[0,1]\right\}_{t=0}^{\infty}$ is an allocation, with the relationship between $c_{t}$ and $c_{t}(j)$ given by (2). A price system is a list of time paths $\left\{P_{t}, W_{t}, P_{t}(j), V_{t}^{j}, v_{t}^{j}, j \in[0,1]\right\}_{t=0}^{\infty}$, with the relationship between $P_{t}$ and $P_{t}(j)$ given by (4) and the relationship between $P_{t}(j), V_{t}^{j}$ and $v_{t}^{j}$ given by (14). Finally let $f_{t}=b_{t}+h_{t}$, the economy's overall level of net foreign assets. Then equilibrium is defined as follows:

A perfect foresight equilibrium given $f_{0}$ is an allocation, a price system, and a government policy such that (a) given the government policy and the price system, the allocation solves the household's problem of maximizing (5) subject to (6) and (8), with (6) 
binding, (b) given the government policy, the restrictions on price setting, and the sequences $\left\{P_{t}, W_{t}, c_{t}\right\}_{t=0}^{\infty}$, the sequences $\left\{V_{t}^{j}, v_{t}^{j}, y_{t}(j), l_{t}(j), j \in[0,1]\right\}_{t=0}^{\infty}$ solve firms' problem of maximizing (15) subject to (12) and (16),

(c) the nontradable goods market clears for all goods and at all times,

$$
y_{t}(j)=c_{t}(j) \quad \forall t, \forall j \in[0,1],
$$

(d) the labor market clears at all times,

$$
L_{t}=\int_{0}^{1} l_{t}(j) d j \quad \forall t
$$

Equations (34), (8) holding with equality, and the definition of equilibrium imply that the following aggregate budget constraint must hold:

$$
f_{0}+\frac{y^{*}}{r}=\int_{0}^{\infty} c_{t}^{*} e^{-r t} d t
$$

Combining this constraint with the first order condition (9) one can derive the path of tradables consumption. This is of course trivial for the permanent stabilization policy, where we have

$$
c_{t}^{*}=y^{*}+r f_{0} \quad \forall t .
$$

For the temporary stabilization policy tradables consumption depends on lifetime income and the entire future path of nominal interest rates. Let $i^{h}=r+\varepsilon^{h}$ and $i^{l}=r+\varepsilon^{l}$. Then there is a consumption boom for $t \in[0, T)$ and reduced consumption for $t \in(T, \infty)$ by

$$
c_{t}^{*}=\left(y^{*}+r f_{0}\right)\left\{\left(1+\alpha i_{t}\right)\left(\frac{1-e^{-r T}}{1+\alpha i^{l}}+\frac{e^{-r T}}{1+\alpha i^{h}}\right)\right\}^{-1} .
$$

Note that the equilibrium paths of tradables consumption and therefore of net foreign assets can be computed independently from the rest of the economy because they are functions only of endowments $\left(f_{0}\right.$ and $\left.y^{*}\right)$ and of exogenous world and policy variables ( $r$ and $\varepsilon_{t}$ ). This will be useful in computing the equilibrium of the nontradable goods market.

\section{E. Complete Dynamic System}

The results of the previous subsection can be used to derive a differential equation for the $\log$ of real marginal cost $\xi$ from (11). We begin by linearizing the equation around the 
steady state, obtaining

$$
\left(\xi_{t}-\bar{\xi}\right)=\left(\ln c_{t}-\ln \bar{c}\right)+\frac{\alpha}{1+\alpha \bar{l}}\left(\varepsilon_{t}-\bar{\varepsilon}\right)+\frac{\bar{L}}{1-\bar{L}}\left(\ln L_{t}-\ln \bar{L}\right) .
$$

To make further progress we have to establish a relationship between $c$ and $L$. It is shown in Appendix I that $\bar{L}=\bar{c}$ and that, after linearizing, one obtains

$$
\ln L_{t}-\ln \bar{L}=\ln c_{t}-\ln \bar{c}
$$

Therefore (42) simplifies to

$$
\left(\xi_{t}-\bar{\xi}\right)=\frac{1}{1-\bar{c}}\left(\ln c_{t}-\ln \bar{c}\right)+\frac{\alpha}{1+\alpha \bar{l}}\left(\varepsilon_{t}-\bar{\varepsilon}\right) .
$$

Note that the steady state value $\bar{c}$ is in fact a strictly decreasing function of the exogenous steady state nominal interest rate $\bar{\imath}$. This reflects the negative effect of deviations from the Friedman rule on steady state output, which can be seen in the steady state version of (11) and which will play an important part in the welfare analysis:

$$
\frac{\bar{c}}{1-\bar{c}}=\frac{(\sigma-1)(1-\gamma)}{\sigma \kappa}(1+\alpha \bar{\imath})^{-1}
$$

Next we linearize equation (10) to obtain the first term of equation (44):

$$
\left(\ln \left(c_{t}\right)-\ln (\bar{c})\right)=\left(\ln \left(c_{t}^{*}\right)-\ln \left(\bar{c}^{*}\right)\right)+\left(\ln \left(e_{t}\right)-\ln (\bar{e})\right) .
$$

To derive a differential equation for $\xi_{t}$ note first that, given (9) and our assumptions about government policy, exchange rate depreciation and the tradables consumption profile are always flat so that $\dot{\varepsilon}_{t}=0$ and $\dot{c}_{t}^{*}=0$. Secondly, for the real exchange rate we have

$$
\left(\ln e_{t}\right)=\varepsilon_{t}-\pi_{t}
$$

Therefore we finally obtain

$$
\dot{\xi}_{t}=-\left(\frac{1}{1-\bar{c}}\right)\left(\pi_{t}-\bar{\varepsilon}\right)+\left(\frac{1}{1-\bar{c}}\right)\left(\varepsilon_{t}-\bar{\varepsilon}\right) .
$$

A key question for dynamic stability is whether $\xi_{t}$ is a predetermined variable. We return to equation (44) and consider the possibility of jumps at time 0 . For the excess demand component we consider (46). The real exchange rate is predetermined under predetermined 
nominal exchange rates and sticky prices. The tradables consumption path exhibits a jump at time 0 under a temporary stabilization, but this is a function only of exogenous lifetime resources and government policies. This makes excess demand a predetermined variable. See Ghezzi (2001) and Calvo and Vegh (1994) for similar arguments. The argument for tradables consumption also applies to jumps in $\varepsilon_{t}$ in equation (44) - these are exogenous to the rest of the economy. Therefore $\xi_{t}$ is a predetermined variable, along with $\psi_{t}$. The variables $v_{t}$ and $\pi_{t}$ are free to jump at time 0 . The full dynamic system for this economy is represented by equations (30), (33), (32) and (48). In matrix form it looks as follows:

$$
\left[\begin{array}{c}
\dot{\psi}_{t} \\
\dot{v}_{t} \\
\dot{\pi}_{t} \\
\dot{\xi}_{t}
\end{array}\right]=\left[\begin{array}{cccc}
-\delta & \delta & 0 & 0 \\
\frac{(\delta+r)^{2}}{\delta} & 0 & -\frac{(\delta+r)^{2}}{\delta} & (\delta+r)^{2} \\
-(3 \delta+2 r) & 2 \delta & (\delta+2 r) & -2 \delta(\delta+r) \\
0 & 0 & -\frac{1}{1-\bar{c}} & 0
\end{array}\right]\left[\begin{array}{c}
\left(\psi_{t}-\bar{\varepsilon}\right) \\
\left(v_{t}-\bar{\varepsilon}\right) \\
\left(\pi_{t}-\bar{\varepsilon}\right) \\
\left(\xi_{t}-\bar{\xi}\right)
\end{array}\right]+\left[\begin{array}{c}
0 \\
0 \\
0 \\
\frac{1}{1-\bar{c}}
\end{array}\right]\left(\varepsilon_{t}-\bar{\varepsilon}\right)
$$

In Appendix II we prove that this system has two eigenvalues with positive real parts and two with negative real parts. Given our results about the number of predetermined variables this proves that the system is saddle path stable. It can further be shown numerically that for a very large range of relevant parameter values ${ }^{6}$ all roots are real.

\section{Model Solution and Discussion}

In this section we compute solution paths for the model after assigning the parameter values shown in Table 1. The time unit for calibration of stock-flow ratios is one quarter. The average length of price quotations of three quarters implied by $\delta=1 / 3$ is reasonable, see the evidence cited in Obstfeld and Rogoff (1996, chapter 10). The exchange rate target $\varepsilon^{l}=10 \%$ p.a. is very close to many current inflation targets in Latin America. Temporary policies will be assumed to have a duration $T$ of three years. Inverse velocity $\alpha$ is set equal to the ratio of real monetary base to quarterly absorption in Brazil in 1996. A 50\% share

\footnotetext{
6 We searched over $\delta \in[0.05,2]$ and $\sigma \in[3,13]$, leaving all other values at those used below in the calibrations.
} 
of tradables in consumption $\gamma$ is empirically reasonable, see De Gregorio, Giovannini and Wolf (1994). For an emerging economy the real marginal cost of borrowing in international capital markets is given by the real Brady bond yield, which at most times fluctuates between $10 \%$ and $15 \%$ for Brazil and Mexico. After adjusting for US inflation this suggests using $r=10 \%$. The value for the proportion of time spent working $\bar{L}=1 / 3$ is based on the evidence cited in Cooley and Prescott (1995). We assume that this is the value associated with the high inflation steady state, and compute the larger value associated with low inflation from (11).

\begin{tabular}{|l|l|l|}
\hline Parameter & Value & Description \\
\hline$\delta$ & $1 / 3$ & Inverse of average contract length in quarters (3) \\
\hline$\sigma$ & 4.33 & Elasticity of substitution \\
\hline$\varepsilon^{h}$ & $20 \%$ p.a. & Initial exchange rate depreciation \\
\hline$\varepsilon^{l}$ & $10 \%$ p.a. & Exchange rate depreciation during stabilization \\
\hline$T$ & 12 quarters & Duration of policy for temporary case \\
\hline$\alpha$ & 0.3 & Inverse velocity \\
\hline$\gamma$ & 0.5 & Share of tradables in consumption \\
\hline$r$ & $10 \%$ p.a. & Real international interest rate \\
\hline$L$ & $1 / 3$ & Proportion of time spent working \\
\hline & & in the high inflation steady state \\
\hline$y^{*}$ & $1 / 3$ & Tradables endowment \\
\hline$f_{0}$ & 0 & Initial net foreign assets \\
\hline
\end{tabular}

Table 1: Parameter Values

To obtain an initial steady state real exchange rate of 1 we normalize the tradables endowment to $y^{*}=\bar{L}=\bar{c}$. Note however that for the purpose of presenting computed solution paths in Figures 2, 3 and 4 we renormalize the initial steady state values of tradables and nontradables consumption to 1 . Initial net foreign assets are assumed to be zero. The log-linear specification of the utility index implies an intertemporal elasticity of substitution of one. Empirical estimates of this elasticity are typically below one, as in Reinhart and Vegh (1995). However, see Ogaki and Reinhart (1998) and Eckstein and Leiderman (1992) for examples of estimates closer to one. 


\section{A. Permanent Policies}

Figure 2 shows equilibrium paths for an unanticipated permanent inflation stabilization from $20 \%$ p.a. to $10 \%$ p.a. In a conventional sticky price model this would have no real effects, and aggregate inflation would immediately jump to $10 \%$. Our results are very different. Inflation $\pi$ cannot immediately jump to the new lower level as a major component of current inflation is the weighted average of past firm-specific inflation rates $\psi$, which immediately starts to decline but cannot jump. The other component of $\pi$ is the relative price set by current price setters, which in the current calibration however only gives rise to a minimal initial jump in inflation. Combined with the immediately lower exchange rate depreciation this stickiness in nontradables inflation implies that the real exchange rate appreciates sharply, i.e. the relative price of nontradables rises sharply. This gives rise to a fairly long-lived nontradables recession of around a two-year duration. The recession reaches its lowest point, an output loss of around $2 \%$, at the time nontradables inflation starts to undershoot exchange rate depreciation, thereby starting to depreciate the real exchange rate to its new equilibrium level. This level is higher than the initial one because in the new steady state nontradables output is permanently higher, reflecting the efficiency gain resulting from a reduction in the monetary distortion to the consumption-leisure choice, see equation (45). Disinflation therefore entails temporary output costs and long-run permanent output gains. A welfare-theoretic evaluation of this trade-off is undertaken in Section IV.

\section{B. Temporary Policies}

As documented by Vegh (1992), emerging market inflation stabilization programs have typically been characterized by early consumption booms in both tradables and nontradables, not by recessions. One of the most popular explanations, first advanced by Calvo (1986), is lack of credibility modelled as policy temporariness. See Calvo and Vegh (1999) for a survey of this literature. 

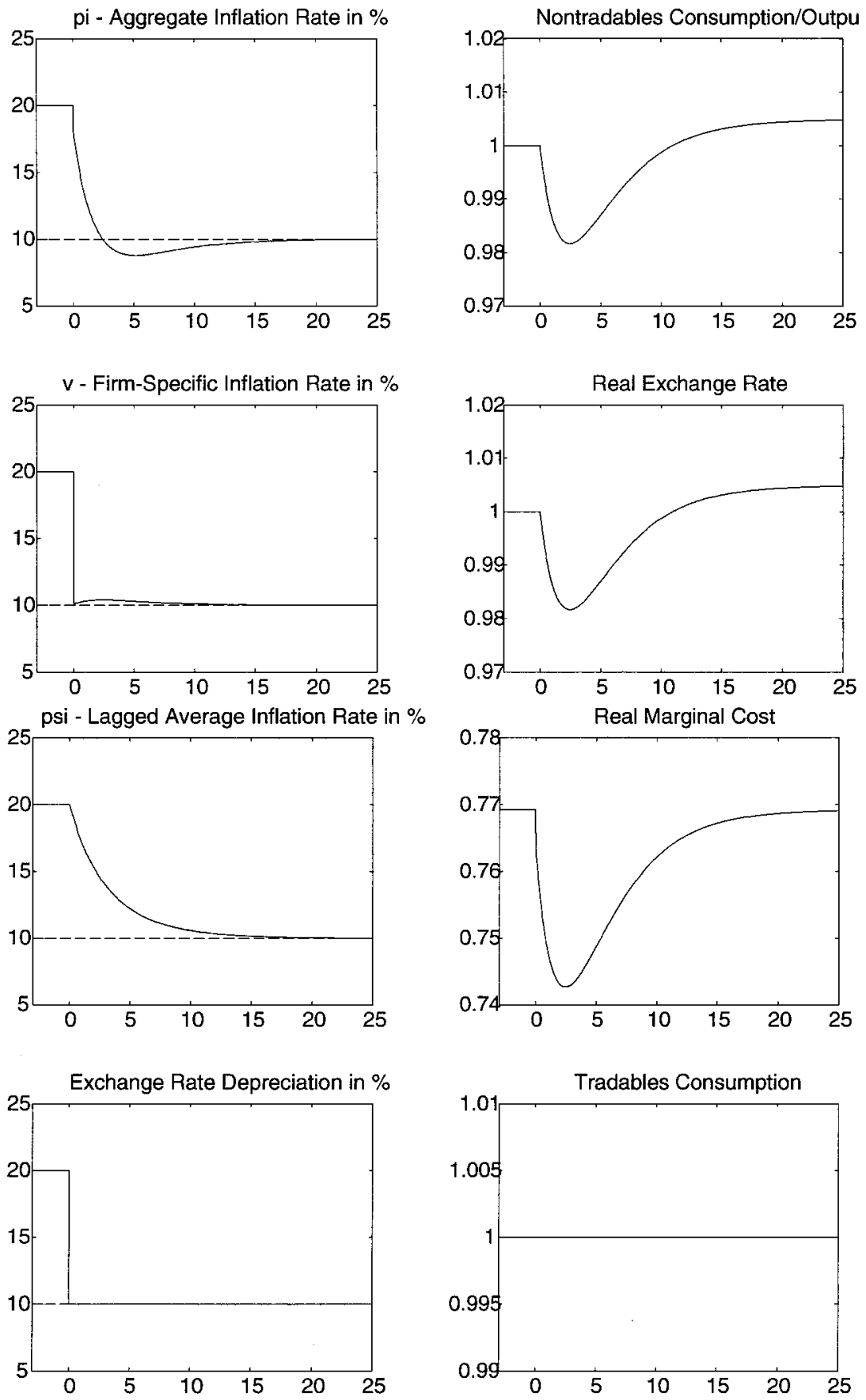

Figure 2 : Permanent Stabilization 
Figure 3 explores this scenario. It shows that temporariness gives rise to a consumption boom in tradables due to intertemporal substitution. But the nontradables sector almost immediately enters a recession due to the real exchange rate appreciation associated with the slow reduction in nontradables inflation. Around the middle of the program inflation begins to undershoot exchange rate depreciation, as in the case of a permanent policy, and at that time output recovers almost fully. Eventually however, well before the final collapse of the program, inflation rebounds due to the anticipation of a reversion to a high inflation steady state, leading to a renewed real appreciation and recession. When the policy collapses and exchange rate depreciation returns to its high steady state, nontradables inflation takes some time to follow suit. During this time the real exchange rate therefore depreciates, and the recession ends a few quarters later.

One troubling aspect of these results is the negative growth rate of nontradables consumption, which is contrary to the findings of Vegh (1992). Uribe (1999) shows that this is a consequence of assuming intertemporally separable preferences, and that habit persistence generates the empirically observed hump-shaped response. It is however worth pointing out that Vegh's (1992) stylized facts relate to very large inflation stabilizations while our stabilization experiment is comparatively moderate. As discussed in more detail below, output responses to large and moderate disinflations have empirically been found to be very different.

Figure 4 illustrates a third scenario. Many emerging markets' monetary policies have historically been characterized by repeated stop-go cycles between high inflation periods and stabilization attempts. It is therefore natural to consider an illustrative experiment where the public fully anticipates a failed stabilization:? The economy enters a high inflation period ( $40 \%$ p.a.) at time 0 , and the public expects this to last for 2 years and to be followed by an exchange rate based stabilization ( $10 \%$ p.a.) that collapses after a further 3 years.

\footnotetext{
$7 \quad$ We thank Michael Mussa for suggesting this exercise.
} 

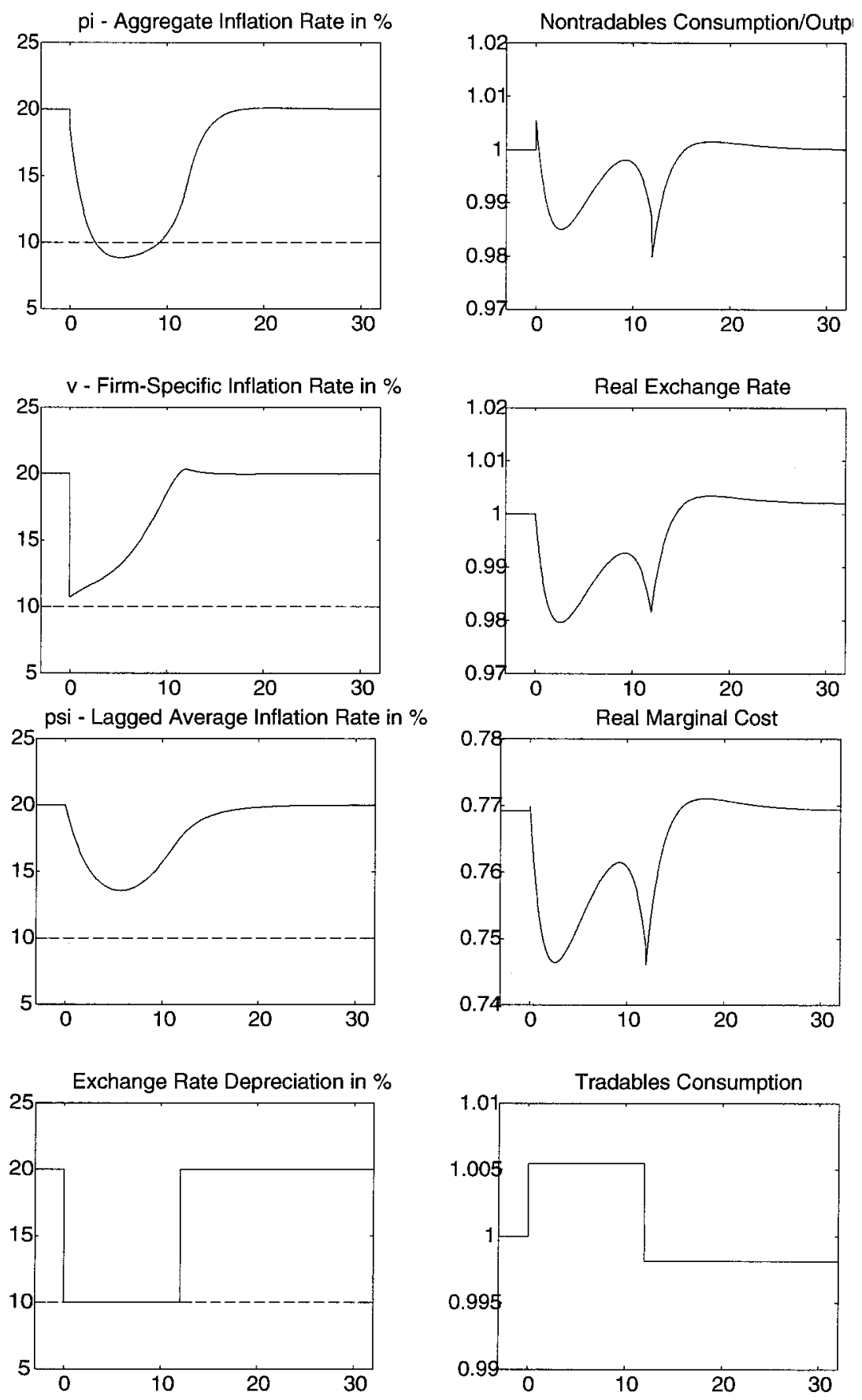

Figure 3 : Temporary Stabilization 

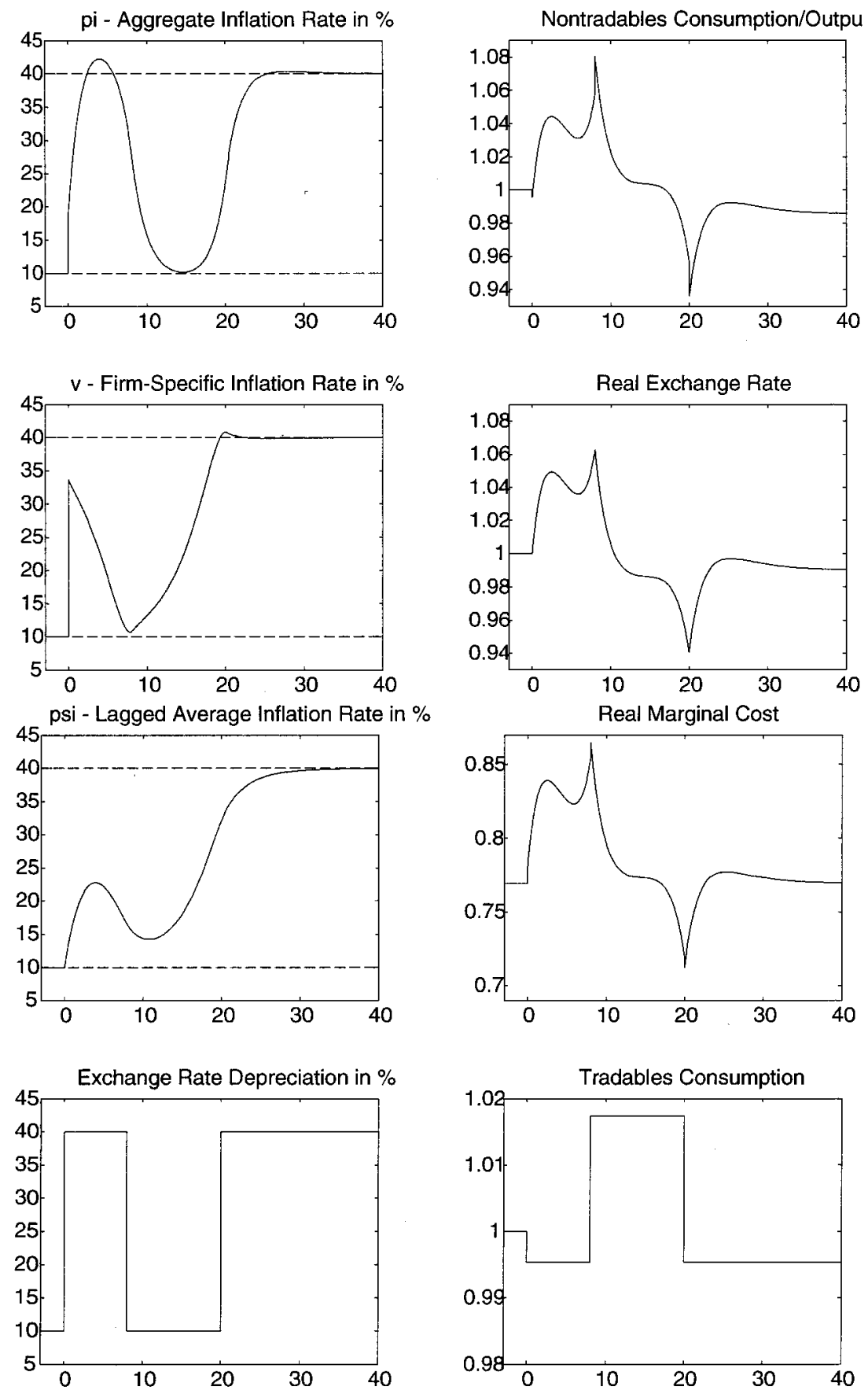

Figure 4 : Stop-Go Monetary Policies 
The implications of this experiment for the real exchange rate are consistent with the findings of Kamin (2001) for the 1988 Mexican and the 1990 Argentinian stabilization. By the time the stabilization starts the real exchange rate is highly undervalued. It then appreciates and is highly overvalued at the time of the program's collapse. However, the behavior of nontradables output is again inconsistent with the experience of historical large stabilizations, for the same reasons mentioned in our discussion of Figure 3.

\section{Welfare}

\section{A. Methodology and Results}

In analyzing the effects of a permanent and fully credible disinflation policy in the previous section, it was found that there are short-term welfare costs mainly due to temporary nontradables output losses, and longer-term welfare benefits due to higher steady state output following the reduction in the monetary distortion to the consumption-leisure choice. The appropriate metric to evaluate this trade-off is the compensating variation in lifetime consumption introduced by Lucas (1987). The net welfare gain accomplished by a permanent reduction in the rate of exchange rate depreciation is defined as the fraction $\theta$ by which consumers' original steady state consumption basket $\bar{c}^{* \gamma} \bar{c}^{1-\gamma}$ would have to be increased to make them indifferent between their lifetime utility in the old, high inflation steady state and the lifetime utility achieved along the equilibrium path to the new, low inflation steady state. To quantify the former we use the calibration $\bar{L}=1 / 3$ and $\bar{L}=\bar{c}=\bar{c}^{*}$. For the latter we use a first-order approximation consistent with our solution method of linearizing around the final steady state $\bar{c}_{\infty}=\bar{L}_{\infty}$. We obtain the following relationship determining $\theta$ :

$$
\begin{gathered}
\int_{0}^{\infty}\left[\gamma \ln \left(c_{t}^{*}\right)+(1-\gamma) \ln \left(c_{t}\right)+\kappa \ln \left(1-\bar{c}_{\infty}\right)-\frac{\kappa \bar{c}_{\infty}}{1-\bar{c}_{\infty}}\left(\ln c_{t}-\ln \bar{c}_{\infty}\right)\right] e^{-r t} d t \\
=\frac{1}{r}\left(\ln \left(\frac{1}{3}\right)+\kappa \ln \left(\frac{2}{3}\right)+\ln \left(1+\frac{\theta}{100}\right)\right) .
\end{gathered}
$$


For the permanent stabilization policy shown in Figure 2 this calculation produces a small net welfare gain of $0.0124 \%$. This is so despite the fact that such a policy is biased against disinflation because the very rapid nature of disinflation leads to a particularly severe real appreciation and therefore nontradables recession. To obtain more general results we therefore consider gradual linear disinflation policies of the following form:

$$
\begin{array}{r}
\dot{\varepsilon}_{t}=-\eta \quad \text { for } t<\left(\varepsilon^{h}-\varepsilon^{l}\right) / \eta, \\
0 \text { for } t \geq\left(\varepsilon^{h}-\varepsilon^{l}\right) / \eta,
\end{array}
$$

where the parameter $\eta$ characterizes the speed of disinflation. We also explored the effect of different degrees of price stickiness by varying the parameter $\delta$. The results are presented in Figure 5 below in terms of contours of net utility gains. The horizontal axis is the overall length of the disinflation period or degree of gradualism $\left(\varepsilon^{h}-\varepsilon^{l}\right) / \eta$ while the vertical axis is the average contract length or degree of price stickiness $1 / \delta$. The figure shows that, for reasonable average contract lengths of up to four quarters, a disinflation from $20 \%$ p.a. to $10 \%$ p.a. produces small net welfare gains of around $0 \%-0.05 \%$. These gains are always decreasing in the degree of price stickiness, and for the chosen parameter range they are increasing in the degree of gradualism. The main effect of greater degrees of price stickiness is to deepen and prolong the nontradables recession. For any given degree of price stickiness, greater gradualism causes a milder real appreciation and therefore a less deep nontradables recession. For the range of parameter values shown in Figure 5 this more than compensates for two opposing effects - more gradualism also leads to greater intertemporal substitution in tradables and it causes the new less distorted steady state to be reached later. For very large degrees of gradualism the latter effect prevails, meaning that the welfare contours eventually bend downwards.

The welfare loss attributable to the nontradables recession alone can be computed by letting the size of the monetary distortion, or $\alpha$, go to zero. This loss is close to zero for low degrees of price stickiness, and reaches around $0.05 \%$ for a rapid disinflation and 
average contract lengths near 4. Larger $\alpha$, on the other hand, increase the overall welfare gain of disinflation. They also reduce the benefits of gradualism because they make it more desirable to reach the new steady state earlier. For $\alpha=1.0$ the welfare gains in Figure 5 would range from $0.13 \%$ to $0.20 \%$, with an optimum length of disinflation period between one quarter for low degrees of price stickiness and 8 quarters for average contract lengths near 4.

The same qualitative results hold for any size of inflation transition in our model. Whether an exchange rate based inflation stabilization is welfare improving depends on the size of the monetary distortion and the degree of price stickiness, with the degree of gradualism in disinflation policy allowing some further trade-offs. The minimum possible rate of steady state exchange rate depreciation is given by the Friedman rule $-r$, which is also the welfare maximizing steady state. This is in contrast to a recent literature ${ }^{8}$ which, using a framework where firms can only choose a price level, finds that the welfare maximizing steady state minimizes relative price dispersion and is therefore found close to zero inflation, not at the Friedman rule. Our model shows that this result does not hold if firms are allowed to choose pricing policies instead of price levels.

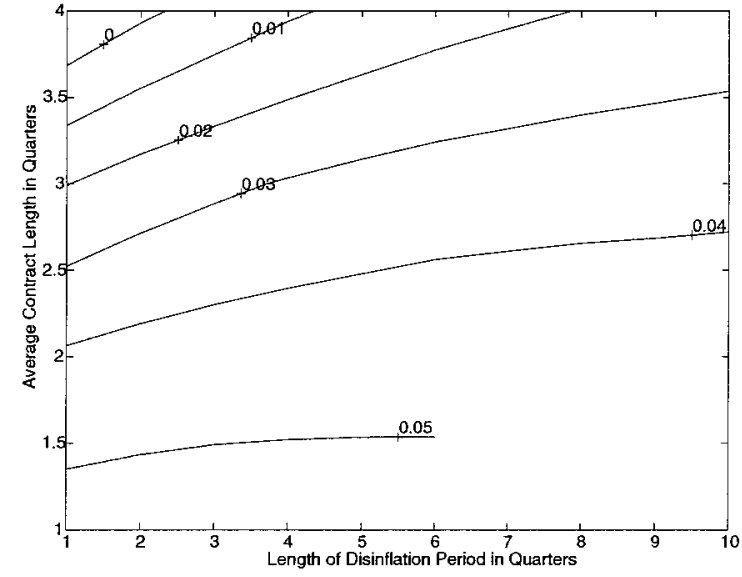

Figure 5 : Welfare Gains in $\%(\alpha=0.3)$

\footnotetext{
8 See King and Wolman (1996) for an early example.
} 


\section{B. Implications for Future Research}

The model we have proposed exhibits two key characteristics, inertia of the inflation rate and a significant output sacrifice. We know from Ball (1991), Gordon (1982) and Gordon and King (1982) that disinflation from moderate levels of initial inflation in industrialized countries do indeed take time and have significant output costs. Many emerging markets are currently embarking on such disinflations, and it is for such circumstances that we consider our model to be most appropriate. But importantly, inflation inertia and output losses are not observed when initial inflation levels are very high. We have known at least since Sargent (1986) that hyperinflations have been stopped at very low output costs, as suggested by the conventional sticky price model. And from Vegh (1992) and others we know that many of the inflation stabilization episodes in extremely high inflation emerging markets were characterized by a consumption boom in both tradables and nontradables, not an almost immediate nontradables recession as suggested by our results.

No single model is currently capable of rationalizing all of these observations. Their shared characteristic is that they treat the speed of disinflation and the rate at which firms update pricing policies as independent parameters. Endogenizing the relationship between these two factors should be an important objective of future research, including our own.

\section{Conclusion}

This paper has proposed a theory of inflation inertia in an environment of maximizing, rational, forward-looking agents. It has set out a way to reconcile models of price rigidities with important empirical regularities that have so far been hard to explain - endogenous inertia of the inflation rate and output losses during moderate disinflation programs. In the proposed framework it becomes possible to conduct an explicit welfare analysis of deflations that quantifies the trade-off between recessions and efficiency gains. Under reasonable parameterizations the latter were found to be larger. As a by-product it was also 
shown that under the more general price-setting assumptions we propose for economies with nonzero steady state inflation, the Friedman rule remains the optimal steady state policy.

An attractive feature of this approach is that it accomplishes these objectives while otherwise remaining firmly within the 'New Keynesian' modelling tradition. The approach is therefore very suitable for a reevaluation of many questions in monetary policy. This opens up rich possibilities for expanding an already large research agenda. 


\section{The Relationship between Labor Supply and Nontradables Consumption}

We begin by defining the aggregate output index $y_{t}$ as

$$
y_{t}=\left(\int_{0}^{1} y_{t}(j)^{\frac{\sigma-1}{\sigma}} d j\right)^{\frac{\sigma}{\sigma-1}} .
$$

From the definition of equilibrium we know that $y_{t}(j)=c_{t}(j)$ and therefore $y_{t}=c_{t}$. Then (3) and (4) give us

$$
y_{t}(j)=\left(\frac{P_{t}(j)}{P_{t}}\right)^{-\sigma} y_{t}
$$

Next we define the aggregate output quantity index $\tilde{y}_{t}$, using (12) and (38), as

$$
\tilde{y}_{t}=\int_{0}^{1} y_{t}(j) d j=\int_{0}^{1} l_{t}(j) d j=L_{t}
$$

and the alternative price index $\tilde{P}_{t}$ as

$$
\tilde{P}_{t}=\left(\int_{0}^{1} P_{t}(j)^{-\sigma} d j\right)^{-\frac{1}{\sigma}}
$$

Then we can derive the following relationship from (A.1) - (A.4):

$$
L_{t}=\tilde{y}_{t}=\left(\frac{\tilde{P}_{t}}{P_{t}}\right)^{-\sigma} y_{t}=\left(\frac{\tilde{P}_{t}}{P_{t}}\right)^{-\sigma} c_{t} .
$$

This implies that the steady state relationship between labor supply and nontradables consumption/output is

$$
\bar{L}=\bar{c} .
$$

Furthermore, (A.5) can be linearized as

$$
\left(\ln L_{t}-\ln \bar{L}\right)=\left(\ln c_{t}-\ln \bar{c}\right)-\sigma\left(\frac{\tilde{P}_{t}}{P_{t}}-1\right) .
$$

Using (A.4) the linearization of the ratio $\tilde{P}_{t} / P_{t}$ can be shown to equal

$$
\left(\frac{\tilde{P}_{t}}{P_{t}}-1\right)=\int_{-\infty}^{t} \delta e^{-\delta(t-s)}\left(\left(p_{s}-1\right)-\int_{s}^{t}\left(\pi_{r}-v_{s}\right) d r\right) d s .
$$

But from (27) the right-hand side of this equation is zero. For the linearized system we therefore obtain the simple relationship

$$
\left(\ln L_{t}-\ln \bar{L}\right)=\left(\ln c_{t}-\ln \bar{c}\right) .
$$




\section{Roots of the Dynamic System}

The characteristic equation of system (49), for simplicity but without loss of generality evaluated at the original steady state $\bar{c}=1 / 3$, can be derived as

$$
\begin{gathered}
\lambda^{4}-2 r \lambda^{3}+\lambda^{2}\left(r^{2}-3 \delta(\delta+r)\right) \\
+\lambda\left(3 \delta^{2} r+3 \delta r^{2}\right)+\frac{3}{2}\left(\delta^{2}(\delta+r)^{2}\right)=0 .
\end{gathered}
$$

In the following we make use of Theorem 1.2.12 in Horn and Johnson (1985, p. 42). Let the $4 \times 4$ coefficient matrix in (49) be denoted by $A$, and the four roots by $\lambda_{1}, \lambda_{2}, \lambda_{3}, \lambda_{4}$. Then it must be true that

$$
\lambda_{1} \lambda_{2} \lambda_{3} \lambda_{4}=\operatorname{det}(A)=\frac{3}{2}\left(\delta^{2}(\delta+r)^{2}\right)>0 .
$$

There must therefore be zero, two or four roots with negative real part. Furthermore,

$$
\lambda_{1}+\lambda_{2}+\lambda_{3}+\lambda_{4}=\operatorname{tr}(A)=2 r>0 .
$$

This rules out the case of four roots with negative real part. For the final part of the proof, let $\chi_{x, y, z}$ be the $3 \times 3$ principal minor of $A$ associated with columns and rows $x, y$ and $z$. Then the theorem states that the following must hold:

$$
\lambda_{1} \lambda_{2} \lambda_{3}+\lambda_{1} \lambda_{2} \lambda_{4}+\lambda_{1} \lambda_{3} \lambda_{4}+\lambda_{2} \lambda_{3} \lambda_{4}=\chi_{1,2,3}+\chi_{1,2,4}+\chi_{1,3,4}+\chi_{2,3,4} .
$$

For the sake of our argument, let the roots $\lambda_{3}$ and $\lambda_{4}$ have positive real parts. We compute the right-hand side and rewrite the left-hand side of (B.4) to get

$$
\left(\lambda_{1}+\lambda_{2}\right) \lambda_{3} \lambda_{4}+\lambda_{1} \lambda_{2}\left(\lambda_{3}+\lambda_{4}\right)=-3\left(\delta^{2} r+\delta r^{2}\right)<0
$$

The second term on the left-hand side is positive, and therefore we must have

$$
\lambda_{1}+\lambda_{2}<0
$$

This requires that these two roots be either real and negative or complex with negative real parts. As mentioned in the text, it can be established numerically that they are in fact real for all interesting parameter values. The same is true for the positive roots. 


\section{References}

[1] Ball, L. (1991), "The Genesis of Inflation and the Costs of Disinflation", Journal of Money, Credit, and Banking, 23(3), 439-452.

[2] Ball, L. (1994a), "Credible Disinflation with Staggered Price Setting", American Economic Review, 84, 282-289.

[3] Ball, L. (1994b), "What Determines the Sacrifice Ratio?", in: Mankiw, N.G. (ed.), Monetary Policy (Chicago: University of Chicago Press).

[4] Ball, L. (1995), "Disinflation with Imperfect Credibility", Journal of Monetary Economics, 35, 5-24.

[5] Calvo, G.A. (1983), "Staggered Prices in a Utility-Maximizing Framework", Journal of Monetary Economics, 12, 383-398.

[6] Calvo, G.A. (1986), "Temporary Stabilization: Predetermined Exchange Rates”, Journal of Political Economy, 94(6), 1319-1329.

[7] Calvo, G.A., Celasun, O. and Kumhof, M. (2001, forthcoming), "A Theory of Rational Inflationary Inertia", in: P. Aghion, R. Frydman, J. Stiglitz and M. Woodford, eds., Knowledge, Information and Expectations in Modern Macroeconomics: In Honor of Edmund S. Phelps. Princeton: Princeton University Press.

[8] Calvo, G.A. and Vegh, C. (1993), "Exchange Rate Based Stabilization under Imperfect Credibility", in: H. Frisch and A. Worgotter, eds., Open Economy Macroeconomics. London: MacMillan Press, 3-28.

[9] Calvo, G.A. and Vegh, C. (1994), "Stabilization Dynamics and Backward-Looking Contracts", Journal of Development Economics, 43, 59-84.

[10] Calvo, G.A. and Vegh. C.A. (1999), "Inflation Stabilization and BOP Crises in Developing Countries", in: Taylor, J. and Woodford, M., eds., Handbook of Macroeconomics.

[11] Campa, J.M. and Goldberg, L.S. (2001), "Exchange Rate Pass-Through into Import Prices: A Macro or Micro Phenomenon", (Manuscript, Federal Reserve Bank of New York).

[12] Carstens, A.G. and Werner, A.M. (1999), "Mexico's Monetary Policy Framework under a Floating Exchange Rate Regime", Documento de Investigacion, Banco de Mexico, No. 9905.

[13] Celasun, O. (2000a), "Real Effects of Exchange Rate Based Stabilization: The Role of Nominal Rigidities", (Manuscript, University of Maryland at College Park).

[14] Celasun, O. (2000b), "Are Price Setters Forward Looking? Evidence from Mexico and 
Turkey", (Manuscript, University of Maryland at College Park).

[15] Christiano, L.J., Eichenbaum, M. and Evans, C. (1996), "The Effects of Monetary Policy Shocks: Evidence from the Flow of Funds", Review of Economics and Statistics, 78(1), 16-34.

[16] Christiano, L.J., Eichenbaum, M. and Evans, C. (1998), "Monetary Policy Shocks: What Have We Learned and to What End?', NBER Working Papers, No. 6400.

[17] Clarida, R., Gali, J. and Gertler, M. (1999), "The Science of Monetary Policy: A New Keynesian Perspective", Journal of Economic Literature, 37, 1661-1707.

[18] Cooley, T.F. and Prescott, E.C. (1995), "Economic Growth and the Business Cycle" in Cooley, T.F. (ed.), Frontiers of Business Cycle Research (Princeton: Princeton University Press).

[19] De Gregorio, J., Giovannini, A. and Wolf, H.C. (1994), "International Evidence on Tradables and Nontradables Inflation", European Economic Review, 38, 1225-1244.

[20] Eckstein, Z. and Leiderman, L. (1992), "Seigniorage and the Welfare Cost of Inflation: Evidence from an Intertemporal Model of Money and Consumption", Journal of Monetary Economics, 29, 389-410.

[21] Engel, C. (1999), "Accounting for U.S. Real Exchange Rate Changes", Journal of Political Economy, 107(3), 507-538.

[22] Froot, K.A. and Rogoff, K. (1995), "Perspectives on PPP and Long-Run Real Exchange Rates", in Grossman, G. and Rogoff, K. (eds.), Handbook of International Economics, Volume III (Amsterdam: Elsevier).

[23] Fuhrer, J. (1997), "The (Un)Importance of Forward Looking Behavior in Price Setting", Journal of Money, Credit, and Banking, 29, 338-350.

[24] Fuhrer, J. and Moore, G. (1995), "Inflation Persistence”, Quarterly Journal of Economics, 110, 127-159.

[25] Gali, J. and Gertler, M. (1999), "Inflation Dynamics: A Structural Econometric Analysis", Journal of Monetary Economics, 44(2), 195-222.

[26] Gali, J., Gertler, M. and López-Salido, J.D. (1999), "Notes on Estimating the Closed Form of the Hybrid New Phillips Curve", (Manuscript, CREI, NYU and Bank of Spain).

[27] Ghezzi, P. (2001), "Backward-Looking Indexation, Credibility and Inflation Persistence", Journal of International Economics, 53(1), 127-147.

[28] Goldberg, P. and Knetter, M. (1997), "Goods Prices and Exchange Rates: What Have We Learned?", Journal of Economic Literature, 35, 1243-1272.

[29] Goldfajn, I. and Werlang, S.R.C. (2000), "The Pass-Through from Depreciation to 
Inflation: A Panel Study", Banco Central do Brasil Working Paper Series, No. 5.

[30] Gordon, R.J. (1982), "Why Stopping Inflation May Be Costly: Evidence from Fourteen Historical Episodes", in: Hall, R.E. (ed.), Inflation: Causes and Consequences (Chicago: University of Chicago Press).

[31] Gordon, R. and King, S. (1982), "The Output Costs of Disinflation in Traditional and Vector Autoregressive Models", Brookings Papers on Economic Activity, 1, 205-242.

[32] Horn, R.A. and Johnson, C.R. (1985), Matrix Analysis (Cambridge: Cambridge University Press).

[33] Kamin, S.B. (2001), "Real Exchange Rates and Inflation in Exchange-Rate-Based Stabilizations: An Empirical Examination", Journal of Development Economics, 64, 237-253.

[34] King, R.G. and Wolman, A.L. (1996), "Inflation Targeting in a St. Louis Model of the 21st Century", Federal Reserve Bank of St. Louis Review, 78, 93-107.

[35] Lane, P. (2001), "The New Open Economy Macroeconomics: A Survey", Journal of International Economics, 54(2), 235-266.

[36] Leeper, E.M., Sims, C. and Zha, T. (1996), "What Does Monetary Policy Do?", Brookings Papers on Economic Activity, 2, 1-63.

[37] Lucas, R.E. Jr. (1987), Models of Business Cycles (Oxford, New York: Basil Blackwell).

[38] Mendoza, E.G. (2000), "On the Benefits of Dollarization when Stabilization Policy is not Credible and Financial Markets are Imperfect", (Manuscript, Duke University).

[39] Menon, J. (1995), "Exchange Rate Pass-Through", Journal of Economic Surveys, 9(2), 197-231.

[40] Morande, F. and Schmidt-Hebbel, K. (2000), "The Scope for Inflation Targeting in Emerging Market Economies", (Manuscript, Central Bank of Chile).

[41] Obstfeld, M. and Rogoff, K. (1996), Foundations of International Macroeconomics (Cambridge, London: MIT Press).

[42] Ogaki, M. and Reinhart, C.M. (1998), "Measuring Intertemporal Substitution: The Role of Durable Goods", Journal of Political Economy, 106(5), 1078-1098.

[43] Reinhart, C.M. and Vegh, C.A. (1995), "Nominal Interest Rates, Consumption Booms, and Lack of Credibility: A Quantitative Examination", Journal of Development Economics, 46(2), 357-378.

[44] Rotemberg, J. (1982), "Sticky Prices in the United States", Journal of Political Economy, 90, 1187-1211. 
[45] Sargent, T.J. (1986), "The Ends of Four Big Inflations", in: Sargent, T.J., Rational Expectations and Inflation (New York: Harper \& Row).

[46] Sims, C. (1988), "Comments and Discussion", Brookings Papers on Economic Activity, 1, 75-79.

[47] Taylor, J.B. (1979), "Staggered Wage Setting in a Macro Model", American Economic Review, 69(2), 108-113.

[48] Taylor, J.B. (1983), "Union Wage Settlements during a Disinflation", American Economic Review, 73(5), 981-993.

[49] Taylor, J.B. (1998), "Staggered Price and Wage Setting in Macroeconomics", NBER Working Paper, No. 6754.

[50] Uribe, M. (1999), "The Price Consumption Puzzle of Currency Pegs", (Manuscript, University of Pennsylvania).

[51] Vegh, C.A. (1992), "Stopping High Inflation: An Analytical Overview", IMF Staff Papers, 39, 626-695.

[52] Webber, A.G. (1999), "Dynamic and Long-Run Responses of Import Prices to the Exchange Rate in the Asia-Pacific", Asian Economic Journal, 13(3), 303-320.

[53] Woodford, M. (1996), "Control of the Public Debt: A Requirement for Price Stability?", NBER Working Papers, No. 5684.

[54] Yun, T. (1996), "Nominal Price Rigidity, Money Supply Endogeneity, and Business Cycles", Journal of Monetary Economics, 37, 345-370. 